\title{
Os rituais funerários em Lyon na época romana
}

Yves Rolland*

ROLLAND, Y. Os rituais funerários em Lyon na época romana. R. Museu Arq. Etn. 32: 108-119, 2019.

Resumo: Lugdunum, hoje Lyon, na França, foi uma das cidades mais importantes do império romano. O interesse pelo culto romano aos mortos é antigo e se confundiu, a partir do século XVI, com o estudo das inscrições. Dos cerca de 900 textos enumerados em Lyon, os epitáfios representam cerca de 70\% do corpus. Mas, apesar dessa riqueza epigráfica, tivemos que esperar o final do século XX para que restos antropológicos e os depósitos de todo tipo que os acompanham sejam temas de pesquisas por si sós. À luz dessas novas contribuições tentaremos retratar as práticas funerárias de uma potente cidade de província.

Palavras-chave: Lugdunum; Cremação; Inumação; Epitáfios; Mausoléus; Libações.

A cidade de Lugdunum, hoje Lyon na França, foi oficialmente fundada pelos romanos em 43 a.C. Ela se beneficiou do estatuto de colônia de direito romano, com suas vantagens, e de uma posição estratégica favorável ao comércio. Além das estradas, a cidade está na confluência de dois rios navegáveis: o rio Ródano e seu principal afluente, o rio Saône. Os rios tendo sido os principais vetores de transporte de mercadoria até a chegada do trem no século XIX, a cidade foi um verdadeiro cruzamento comercial, fazendo a conexão entre o Sul, o Mediterrâneo e o Norte do império (Estrabão, Geografia, IV, 6, 11). A cidade ganhou também o título de emporium. Lugdunum se tornou a maior cidade das Gálias no segundo século e uma das mais importantes do império. No final

(*) Doutor em arqueologia romana. Pesquisador associado ao laboratório UMR5138 - CNRS / Universidade de Lyon 2 <yrolland04@yahoo.fr> da Antiguidade, quase todos os monumentos foram desmontados e seus materiais foram reciclados em cal ou elementos de arquitetura. A maioria dos epitáfios foi gravada num calcário extremamente compacto, muito sólido, vindo de pedreiras situadas na extremidade sul do Jura.

Durante o Renascimento a cidade se orgulhou do seu passado romano. A partir do século XVI se formaram as primeiras coleções de antiguidades. Dentre elas, muitas inscrições lapidares começaram a ser reunidas. Claude Bellièvre, magistrado (1487-1557), foi um dos primeiros eruditos da cidade a estabelecer um inventário das inscrições, incluindo 45 epitáfios. Outros autores aumentaram este corpus. Gabriel Symeony (1509-1570), homem de letras originário de Florença, relatou, pela primeira vez, outra coisa além de epitáfios, revelando a descoberta de urnas funerárias na margem esquerda do Ródano, no início da via que levava para a Itália. Com Jacob Spon (1647-1685), médico nascido em Lyon, a quem atribuímos a paternidade 
da palavra arqueologia, os epitáfios não foram apenas traduzidos, mas também comentados, os ritos foram explicados. No século XVIII, foram criadas sociedades eruditas, como a Academia de Ciências, Artes e Letras de Lyon, fundada em 1700, e os estudos epigráficos se multiplicaram acompanhando as descobertas (Pérez 1998:158). Cerca de 900 inscrições foram contabilizadas em Lyon, a maior parte gravada na pedra. Das inscrições, 70\% são epitáfios (Savay-Guerraz 2009:63). Considerando a quantidade de inscrições e a densidade de informações nelas contidas, o interesse pelos rituais funerários romanos em Lyon não é apenas antigo, mas também com muito material de estudo.

Em 1885, a extensão de uma linha de trem a oeste, a partir da colina Fourvière, levou à primeira operação de arqueologia funerária em grande escala em Lyon, no bairro de Trion. As bases de dez mausoléus foram assim reveladas, com larguras de até 6m. (Fellague 2009:117124). Ao pé desses monumentos foram descobertas muitas sepulturas, principalmente depósitos de cremação e algumas inumações. As bases de uma arqueologia funerária em Lyon foram, assim, estabelecidas desde o final do século XIX. No entanto, durante a primeira metade do século seguinte, essa disciplina sofreu certa estagnação. Os pesquisadores se orientaram para outros assuntos, principalmente arquitetura e monumentos. As escavações concentraram-se no centro da cidade romana, excluindo as áreas periféricas ocupadas pelas áreas funerárias. Em 1948, a área funerária de Saint-Laurent de Choulans revelou uma grande quantidade de restos ósseos. Pela primeira vez, em Lyon, a idade, o sexo, o tamanho dos esqueletos e as patologias detectáveis nos mesmos foram analisados. A partir da década de 1980, a multiplicação das escavações e o desenvolvimento da arqueologia funerária fizeram parte do movimento mais amplo do desenvolvimento da arqueologia preventiva e de resgate. Além da antropologia, a arqueologia funerária incluiu disciplinas naturalísticas (geomorfologia, análise da vegetação, da fauna etc.) e o uso de métodos laboratoriais (datação, caracterização etc.). Assim, a arqueologia funerária se tornou rapidamente uma especialidade e centenas de sepulturas já foram descobertas em Lyon (Bérard 2005;
Savay-Guerraz 2009). Assim, considerando os dados recolhidos, quais especificidades podem ser destacadas para Lugdunum? Para responder a esta pergunta, tentaremos sintetizar cada uma das etapas do processo funerário reconhecidas nessa cidade.

\section{Se despedir do morto}

\subsection{Velório}

Em Lyon, como no resto do império, os romanos tinham uma forma de medo supersticioso em relação à morte. Isso era vivido como uma conspurcação ou mácula temporária que afetava toda a família do falecido e sua casa, considerada "funesta". Os ritos dos funerais, ou funus, pretendiam pôr fim a esta situação de crise, que terminava apenas com a saída e a inumação do corpo (Poux 2009-2010:15). O morto era exposto em seu leito de morte no átrio, a principal sala de recepção. A sala era decorada com guirlandas de flores e frutas trazidas por parentes (Plínio, História Natural, X, 43), semelhantes às representadas na estela de um morto encontrada em Lyon (CIL XIII, 2120; AD 259).

Difíceis de apreender arqueologicamente, esses rituais exigiam alguns acessórios encontrados nos mobiliários funerários depositados nas sepulturas. Fechar os olhos dos mortos (oculos condere) era, como hoje, a primeira etapa desses ritos (Lucano, Farsália, III, 740). Inúmeros balsamários (unguentários) foram encontrados nas tumbas de Lyon. Eles continham óleos destinados a lavar e perfumar o corpo do falecido, cujo velório podia durar até uma semana, de acordo com a importância social do morto e sua família. Esses unguentos usados no ritual funerário tornavam-se funestos, não podendo ser reutilizados, sendo assim depositados junto ao corpo. Muitas moedas também foram encontradas na boca ou nos olhos dos mortos nos túmulos de Lyon. Este ritual, chamado de "o denário de Caronte”, é copiado dos gregos e tinha a função de pagar a passagem da alma no rio do mundo inferior.

Uma das últimas etapas do velório consistia em fazer uma máscara em gesso do falecido, a fim de guardar uma imagem o mais fiel possí- 
vel do mesmo. A máscara era usada para fazer retratos de cera em positivo do rosto do morto. Uma descoberta excepcional foi feita no século XIX, durante a escavação da rua de Trion: a marca, em relevo, de uma máscara funerária. Um positivo foi feito no momento da descoberta (Fig. 1). A máscara funerária foi depositada junto com o corpo de uma menina em um túmulo encimado por uma inscrição dedicada por sua própria mãe: "aos deuses Manes e em memória de Claudia Victoria, 10 anos, um mês e onze dias de idade". Foram também descobertos objetos pessoais da jovem falecida, como um gancho de cabelo e uma boneca articulada de marfim. A expressão da máscara parece refletir o sofrimento dos últimos momentos da menina (Poux 2009-2010:42).

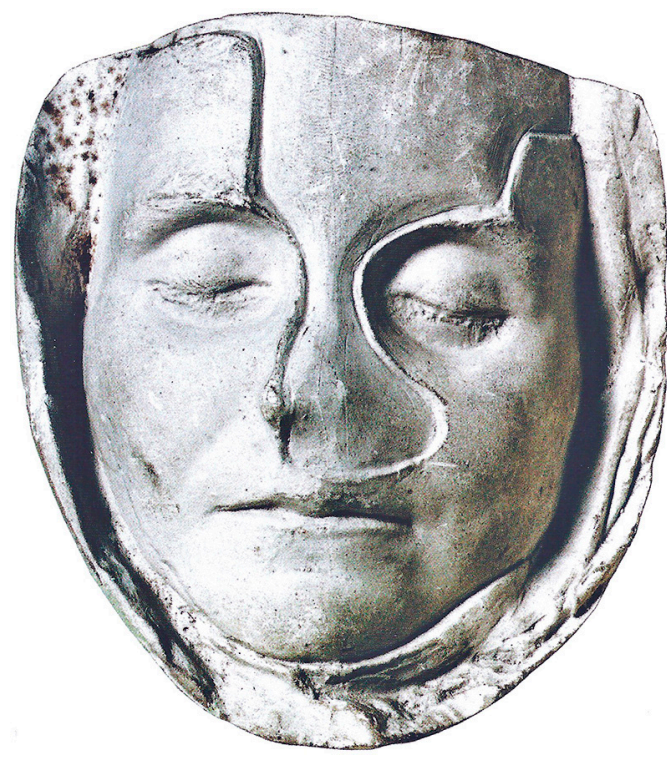

Fig. 1. Máscara de Claudia Victoria. Museu galo-romano de Lyon Fourvière (Poux 2009-2010: 42).

Depois do velório, um cortejo levava o corpo para seu último destino, fora do centro da cidade, mas essa parte não deixou evidências.

\subsection{Espaços funerários}

Em Roma, já no século $\mathrm{V}$ a.C., uma disposição da Lei das Doze Tábuas torna ilícitas as inumações e as cremações dentro da cidade (Cícero, De Leg., 2, 23, 58). Esta separação entre os mortos e os vivos se explica por questões de crença e de higiene. Em Lyon, a arqueologia confirmou a aplicação dessa regra.

Algumas máscaras de larvae foram descobertas em Lyon, provavelmente para ornamentar um monumento funerário ou delimitar áreas de sepultamento, onde tinham uma função apotropaica. Seus rostos assustadores serviam como marcos simbólicos, delimitando o território dos vivos e dos mortos (Poux 2009-2010:28). Por questões semânticas, é melhor não falar de necrópole, a palavra é usada apenas uma vez na literatura antiga (Estrabão, Geografia, XVII, $1,10)$ e designa em Alexandria a "Necropolis", "cidade dos mortos" bem separada do mundo dos vivos. Além disso, o termo "cemitério" deriva da palavra grega "Koimetêrion", "dormitório", seu uso é atestado por grupos de tumbas de mártires em meados do século IV em Roma. Assim, o uso da palavra é geralmente reservado para grupos funerários associados a um santuário cristão (Tranoy 2009:86), com isso é melhor usarmos o termo de zonas funerárias.

Lugdunum ficou no centro de uma rede rodoviária criada por Agripa (Estrabão, Geografia, IV, 6, 11), sendo que a localização dessas primeiras rotas é conhecida em linhas gerais. Sua restituição é baseada na topografia natural, descobertas pontuais de pavimentação e, sobretudo, a posição de tumbas, a maioria dos blocos sendo reutilizados não muito longe de sua localização inicial. $O$ posicionamento das tumbas próximas aos eixos de comunicação se explica pelo fato de que a leitura do epitáfio, supostamente feita pelos viajantes, manteria a memória do morto (Bérard 2009). No entanto, a repartição das tumbas na periferia de $L u g d u$. num mostra que este princípio nem sempre foi seguido (Fig. 2).

O estatuto e a importância de Lugdunum possibilitaram a presença de uma muralha separando a cidade e o mundo dos mortos, mas a existência dela ao redor da colônia é muito controversa e não é apoiada por nenhum texto ou prova arqueológica. As escavações mostram que, na colônia, como em outros lugares, as tumbas não foram guardadas em lugares isolados e protegidos. Os locais escolhidos para receber as sepulturas foram, na maioria das vezes, espaços abertos, em contato com os vivos. 


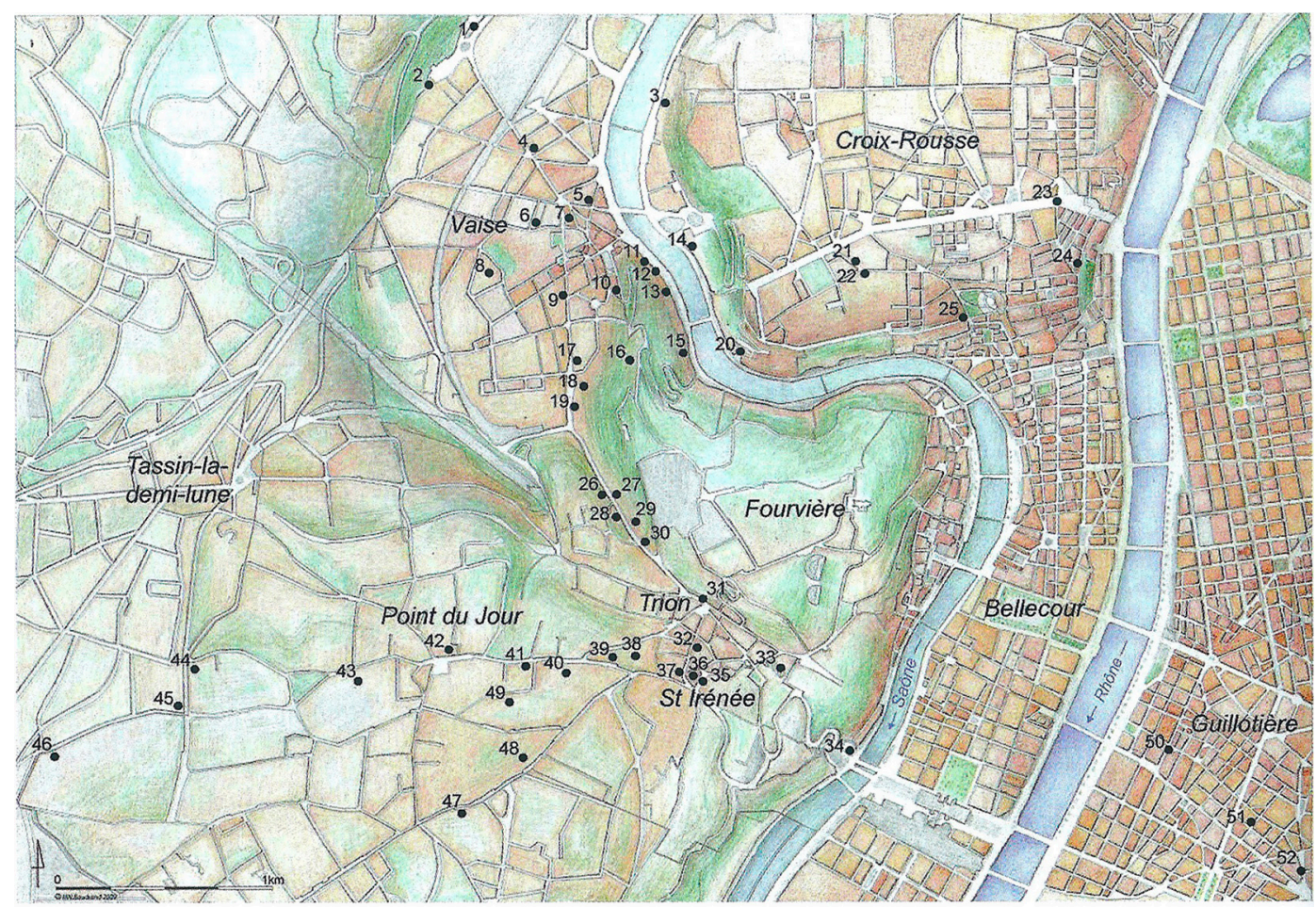

I. périphérique nord- Voie de l'Océan

2. périphérique nord-Voie de l'Océan

3. 48-52 Quai Gillet

4. 30-32 rue de Bourgogne

5. 4-6 rue du Mont d'Or

6. îlot Mas

7. 41-43 rue du Bourbonnais-Villa Montel

8. 9 rue du docteur Horand

9. 38 rue du sergent Berthet

10. 47 rue du Chapeau-Rouge

11. 14 Quai Arloing

12. 21 Quai Arloing

13. 29-30 Quai Arloing

14. 9 Quai Gillet

15. Quai Chauveau-tombeau des Deux-Amants

16. quartier Saint Pierre

17. 51-53 rue du sergent Berthet

18. métro Gorge-de-Loup

19. métro Gorge-de-Loup

20. angle montée de la Butte-quai

Saint Vincent

21. rue des Chartreux

22. 7-9-1I rues des Chartreux

23. place Bellevue

24. 10 rue des Fantasques
25. clinique Saint Charles

26. 54 rue Pierre Audry

27. 77-79 rue Pierre Audry

28. 52 avenue Barthélémy Buyer

29. 101-107 rue Pierre Audry

30. $|17-12|$ rue Pierre Audry

31. mausolées de Trion

32. |9-21 rue des Fossés-de-Trion

33. Saint Just

34. Saint Laurent de Choulans

35. Saint-Irénée

36. rue Trouvée

37. 20 rue des Fossés-de-Trion

38. 25-29 rue de La Favorite

39. 37 rue de La Favorite

40. 62 avenue du Point-du-Jour

41. 53-55 avenue du Point-du-jour

42. 50 avenue du Point-du-Jour

43. 4 I rue Joliot-Curie

44. église Sainte Anne de Ménival

45. Tassin-La Raude

46. 207 rue Joliot-Curie-clos des

cèdres

47. les bruyères et clos Nouvelet

48. 62 rue du Commandant Charcot

49. 19 rue des Granges

50. rue de Marseille-mausolée des

Acceptii

51. angle rue Père Chevrier-Elie

Rochette

52. 40-48 rue de la Madeleine

Fig. 2. Localização dos conjuntos funerários de Lugdunum (desenho de M. Baudroin, In: Tranoy 2009: 84). 
Os resultados das escavações realizadas desde o início da década de 1990 mostram que os túmulos constituíam conjuntos que estavam inseridos nos vazios do tecido urbano, e faziam a transição entre as zonas artesanais, armazéns e casas. Se os caminhos tiveram um inegável papel atrativo, alguns grupos funerários estavam distantes, especialmente os mais modestos, sem monumentos; eles ocupavam, às vezes, lugares úmidos ou até edifícios destruídos (Tranoy 2009:83-106).

\subsection{Banquete funerário}

Para se despedir do morto um banquete costumava ser compartilhado com ele e com os deuses; oferendas eram feitas enquanto os parentes estavam comendo. Em Lyon, as escavações de 1996 conduzidas perto da estrada periférica norte, revelaram fornos rudimentares dos séculos II e III, diretamente cavados no chão e usados para o cozimento de alimentos servidos durante os funerais e as refeições comemorativas nas tumbas. Esses fornos têm uma relação direta com os pedaços de louça e de ânforas descobertos nas covas de depósito nas proximidades. Esses resíduos são testemunhos do que as famílias trouxeram para cozinhar, comer e beber durante a refeição funerária (Blaizot 2009: 156164).

Depois desse momento de despedida, o corpo podia ser queimado ou inumado.

\subsection{Cremação}

As duas possibilidades coexistiram. No início do Império, a cremação foi predominante. No século IV, a prática se inverteu e a cremação foi totalmente abandonada em Lugdunum. Talvez essa mudança tenha uma relação com o desenvolvimento do cristianismo e a necessidade de manter os corpos inteiros para as ressurreições.

O rito de cremação existia na Gália antes da conquista romana, mas ele se generalizou com a romanização. Ele foi majoritário em Lugdunum até metade do segundo século. As maiores piras foram erigidas sobre fossas (Fig. 3), como mostrou, por exemplo, a escavação conduzida na rua do comandante de Charcot em 2001 (século I). Depois da combustão, a fossa contém os restos do falecido, e dos objetos que o acompanhavam. Ao redor do leito fúnebre foram depositados objetos. Os utensílios de mesa representaram uma grande parte dos objetos, até cinquenta recipientes nas piras mais antigas de Lyon. Alguns continham comida (carne, vegetais), bem como frutas, bolos e pães. Muitas vezes encontramos cerâmicas quebradas e parcialmente calcinadas: são os pratos usados durante as cerimônias, depois quebrados na pira durante a combustão. Outros objetos desempenharam um papel especial durante os funerais, como frascos de perfume ou instrumentos de higiene pessoal. Às vezes aparecem pertences pessoais do falecido, muitas vezes mutilados para perecer junto com ele. Certas vezes, instrumentos ligados à profissão do falecido também o acompanhavam na pira, o material de um médico oculista foi descoberto nos restos de uma pira do século III, rua de la Favorite (Boyer 2009; Voinot 2011).

A pira não era a sepultura definitiva. Depois da cremação, uma parte dos ossos costumava ser retirada para ser transportada para outro lugar. Os ossos lavados eram colocados numa urna enterrada (chumbo, cerâmica, vidro ou pedra) ou posta num monumento de pedra. $\mathrm{O}$ cofre de mármore de Aufidia Antiochis, do século I - II é um exemplo (Fig. 4). "Aos deuses Manes de Aufidia Antiochis, seu marido Sextus Aufidius Thiasus fez esta tumba para sua esposa muito cara" (AE, 1976, 452; ILTG 247). Este tipo de monumento por ter um alto custo foi reservado para as elites (Burnand \& Burnand 1976). Outra possibilidade, mais simples, consistia em enterrar a urna, fala-se, então, de depósito de cremação. Em Lyon, vários desses tipos de enterramentos foram revelados. O depósito do meio do século I, da rua Berthet, descoberto em 2000, consista num ossuário colocado em uma cova, acompanhado de vários objetos voluntariamente quebrados: frasco de perfume, jarro (que continha um líquido) e algumas tigelinhas postas em uma prateleira (que continham alimentos sólidos). A análise da forma da cova e da posição dos objetos permitiu concluir que o conjunto não estava coberto de terra, mas ocupava um espaço vazio, provavelmente 


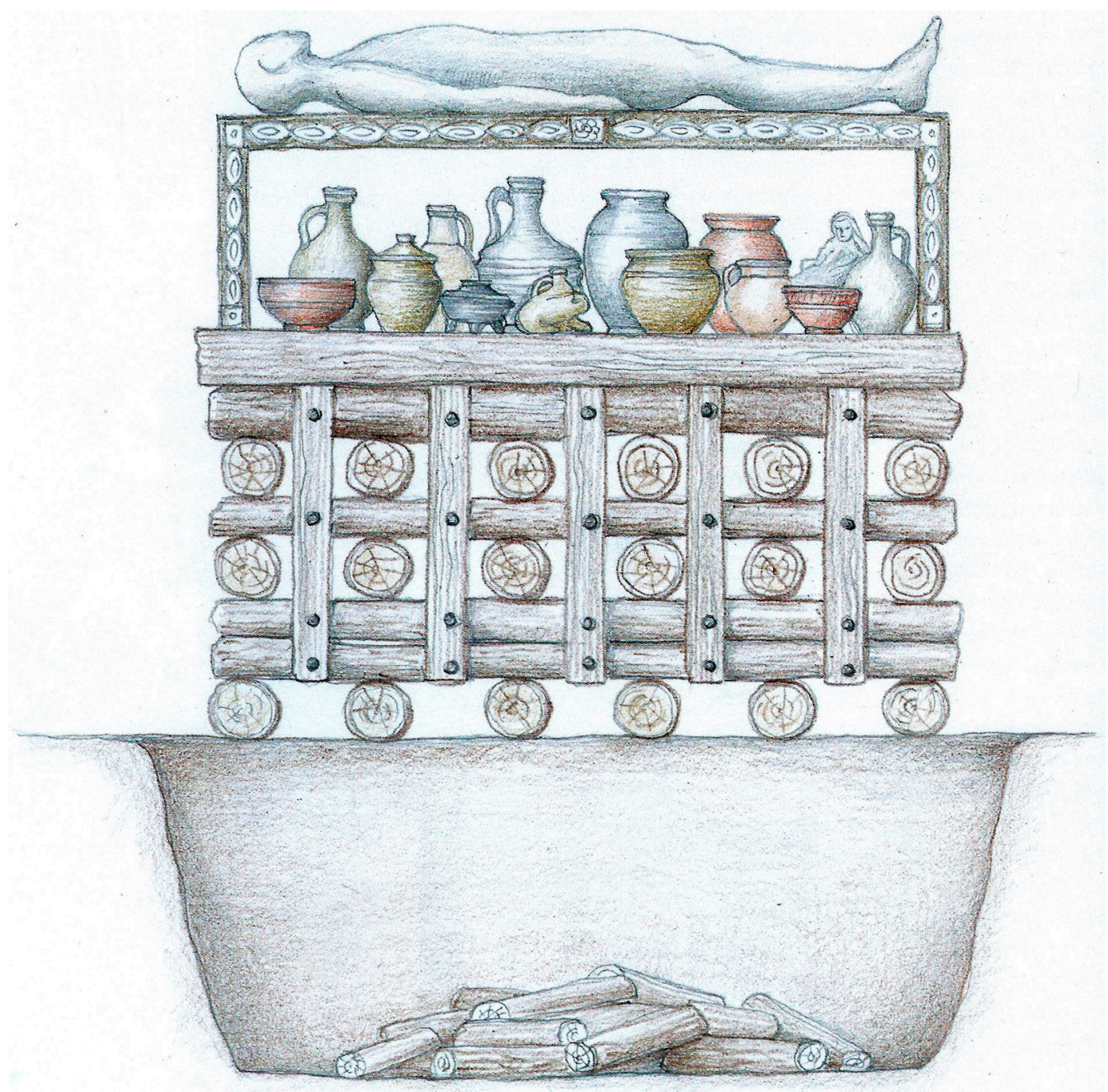

Fig. 3. Restituição de uma pira funerária. Desenho de Marie-Noëlle Baudrand (Blaizot 2009: 154).

sob uma cobertura de madeira. Vários outros depósitos foram escavados e mostram uma grande diversidade de situações. Um depósito do meio do século I, revelado em 2003, rua des Granges, 19, mostra um conjunto de urna / cerâmicas colocado numa caixa de madeira. A tampa podia ser removida para as libações.

\subsection{Inumação}

Se o rito de cremação predomina após a conquista romana, a inumação, que existia anteriormente na Gália, nunca desapareceu totalmente. A tumba da rua du Mont-d'Or, que data da virada para nossa era, analisada em 2009, constituía um exemplo. O corpo estava deitado de lado, debaixo de um cobertor, recipientes estavam colocados numa tampa de madeira, acima do corpo e uma segunda tampa de madeira devia fechar o conjunto.

Durante o final do Império Romano, a cremação foi abandonada (Blaizot 2009), os mortos foram enterrados em covas, caixões de madeira (como o túmulo do século IV descoberto em Arloing Quay, em 1989), caixões de chumbo ou em sarcófagos de pedra. 


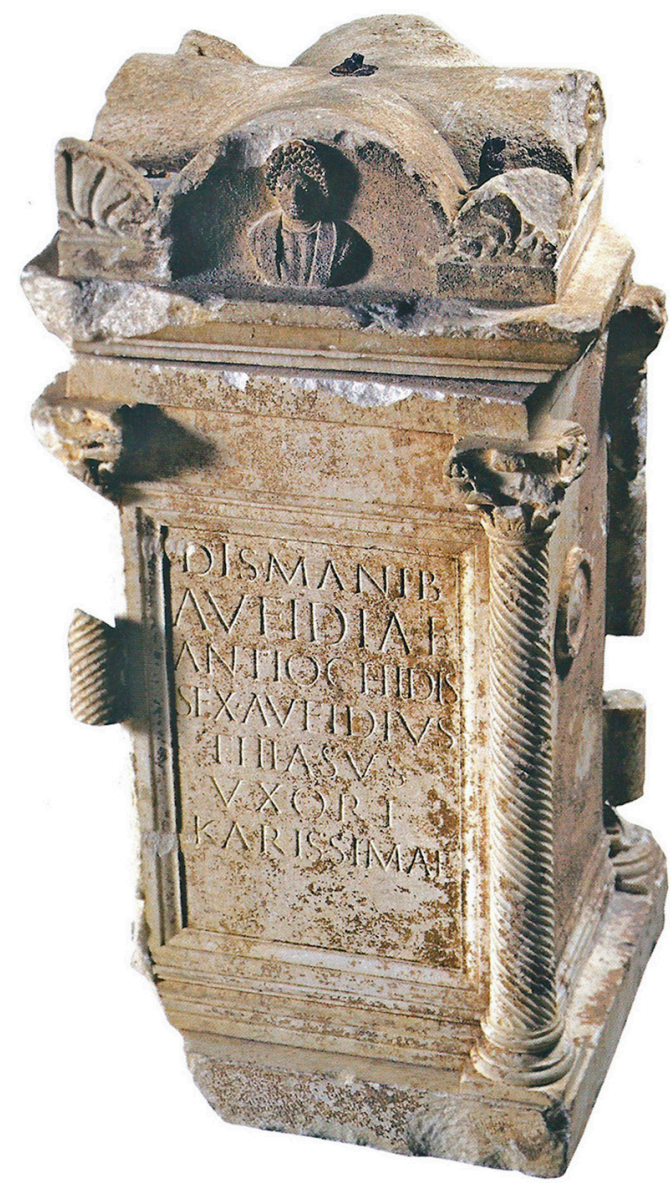

Fig. 4. Cofre de mármore de Aufidia Antiochis (ILTG 247).

As tumbas de crianças muito jovens não eram raras, 20 a $25 \%$ dos bebês não atingiam a idade de um ano. Essas crianças foram sistematicamente enterradas, pois a cremação de um ser humano não era permitida antes da chegada de seus primeiros dentes, já que os dentes eram a garantia de que haveria algo a ser recolhido para ser colocado na urna funerária. Os bebês eram frequentemente enterrados com amuletos, até mesmo fálicos (fascina), destinados a afastar o mau olhado. A sepultura da rua des Fossés de Trion, de meados do século IV, mostra um tipo de sepultura peculiar. Uma ânfora vazia, cuja parte superior foi cortada, foi usada para inumar uma criança de seis meses; a ânfora estava coberta de telhas. Esta prática era comum nos séculos IV e V em Gália Narbonense (Blaizot 2009:174-177).

\section{Comemorar o morto}

\subsection{Epitáfios}

Os epitáfios eram usados para marcar a localização da sepultura. Os textos mais antigos, descobertos em Lyon, são do final do século I a.C. Eles são muito breves e limitam-se ao nome do falecido. Na colina de Fourvière, bairro do Trion, foi descoberta, em 1885, uma estela onde pode-se ler: "Ancharia Bassa, libertada de Quintus, aqui repousa”. (AD 206; CIL, XIII, 2059).

A partir do final do século I aparece frequentemente, nas tumbas de Lugdunum, a representação de uma ferramenta designada em latim pela palavra ascia. Esse utensílio é um tipo de enxó, equipado com um cabo curto, sendo que sua forma parece estar associada ao trabalho da madeira. O texto de vários epitáfios termina pela fórmula "sub ascia dedicavit", a tumba foi dedicada sob a ascia por aquele que cuidou de sua realização (Fig. 5). Desde, pelo menos, o século XVII, os historiadores se perguntam sobre o significado desse instrumento. $O$ papel dele era provavelmente simbólico, mas nenhum texto antigo o menciona. As hipóteses são diversas: espátula para moer a cal para a construção de um túmulo; instrumento para cortar tijolos e cortar pedras das tumbas; instrumento para cortar a madeira da pira; ferramenta de carpinteiro para fazer um toldo para proteger o túmulo; tipo de enxada para escavar a cova; instrumento para golpear a pedra do monumento e consagrá-la; machado que protege contra as violações da sepultura, ameaçando os profanadores; machado, atributo do Mercúrio gaulês psicopompo etc. Apesar de continuar enigmática, a ascia, rara nos epitáfios de Roma, era a norma em Lyon a partir do segundo século (Savay-Guerraz 2009:69-75).

A partir do século II, o monumento funerário geralmente tinha a forma de um altar e os epitáfios às vezes se tornaram longos. A dedicatória aos deuses Manes, abreviada DM para D(iis) $\mathrm{M}$ (anibus), torna-se a regra geral, assim como a menção e representação da ascia. A duração da vida é, algumas vezes, especificada, como pode ser visto no epitáfio de Blandinia Martiola, do século II ou III: "Aos deuses Manes e à memória eterna 


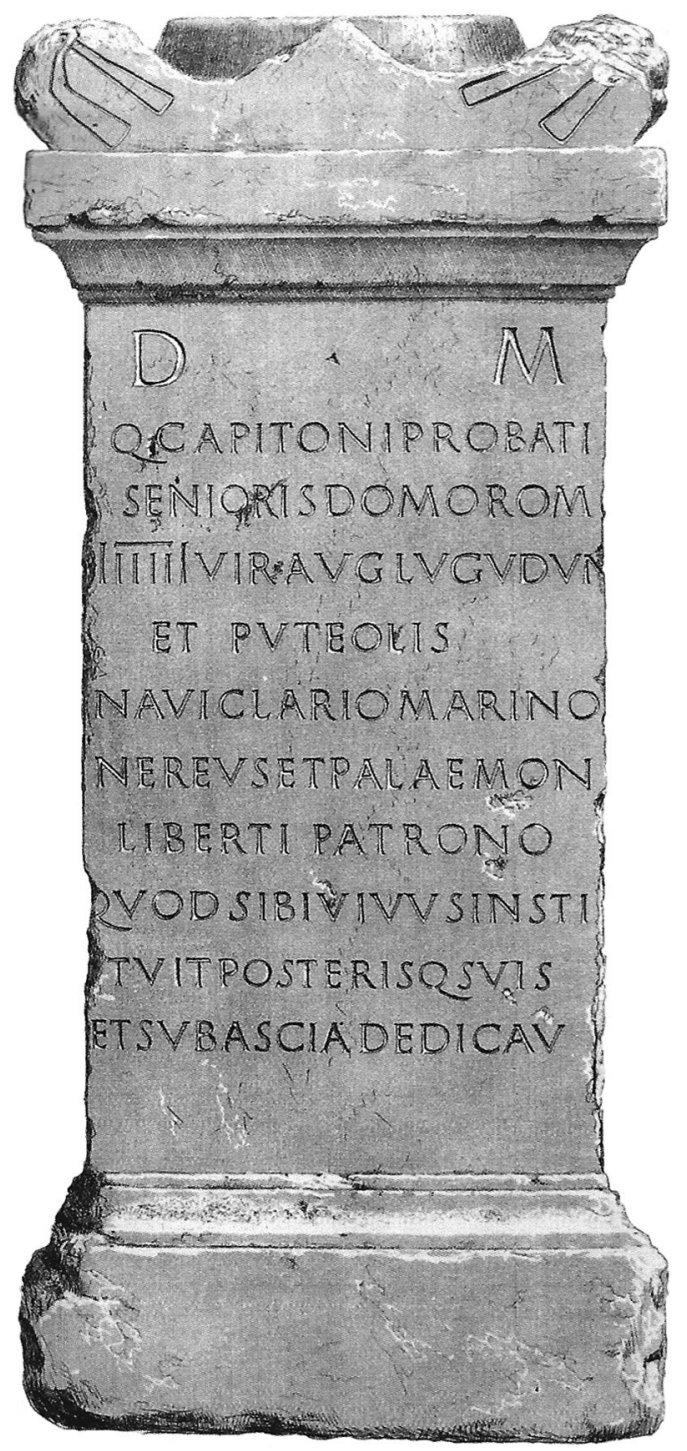

Fig. 5. Epitáfio de Quintus Capitonius Probatus, com ascia dupla. Museu galo-romano de Lyon-Fourvière (CIL, XIII, 1942; AD 159).

de Blandinia Martiola, jovem cheia de inocência, morta aos dezoito anos, nove meses e cinco dias; Pompeu Catussa, da cidade dos Sequanos, artista de estuque, à sua esposa incomparável, cheia de bondade para com ele, que viveu com ele durante cinco anos, seis meses e dezoito dias, pura de toda conspurcação, fez esta tumba e também para si mesmo e dedicou-a sob a ascia. Você que está lendo estas linhas, vai ao banho de Apolo, o que com minha esposa fiz com frequência e ainda faria se fosse possível”. (CIL, XIII, 1983; AD 187).
Ao contrário de outras regiões da Gália, onde o falecido era muitas vezes representado no exercício da sua profissão, a arte funerária de Lugdunum é caracterizada pela sua grande sobriedade. São poucos os retratos funerários conhecidos em Lyon (Laubry 2009: 137). A raridade das imagens é compensada por inscrições de excepcional qualidade de gravura, o epitáfio constituindo o único ornamento do monumento. Entre os raros monumentos com representações, citemos o exemplo da tumba de Primilla (Fig. 6). Este pequeno monumento funerário carrega um curto epitáfio: "Aos deuses Manes, à memória eterna de Primilla, sua filha Terentius Pritto fez [este monumento]" (CIL, XIII, 2242; AD 362 ; NEsp., II, 278). A falecida, adornada com brincos e um colar, é mostrada segurando uma caixa de joias, sinal de riqueza (Laubry 2005:80; Savay-Guerraz 2013: 120).

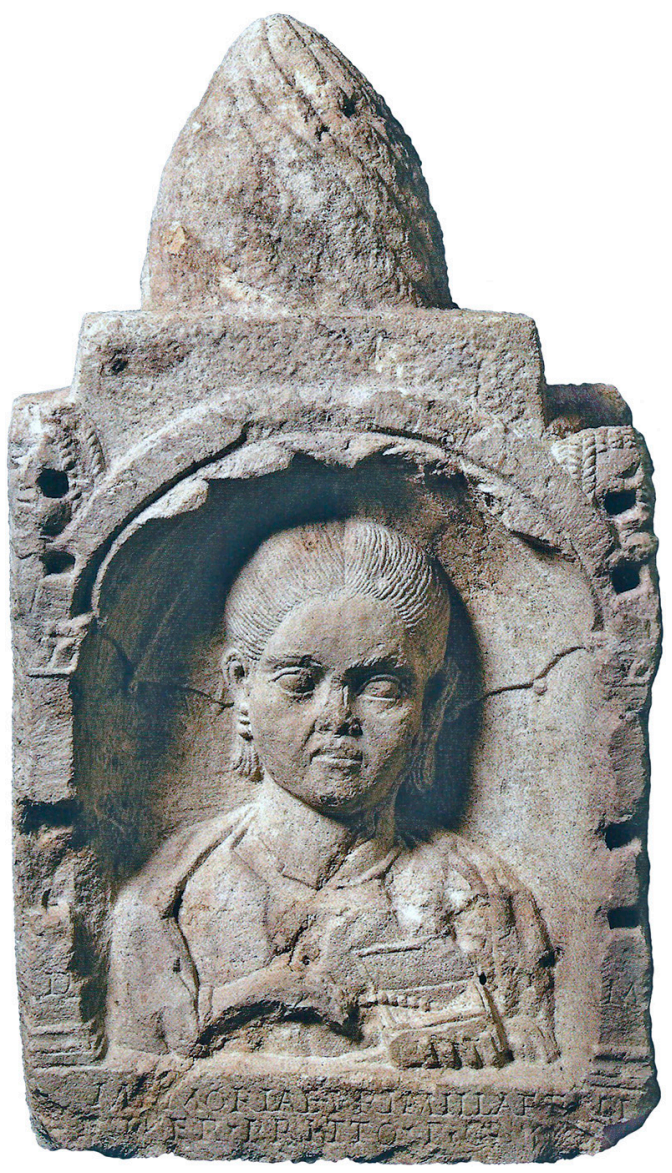

Fig. 6. Estela de Primilla Museu galo-romano de Lyon-Fourvière (CIL, XIII, 2242; AD 362; NEsp., II, 278). 


\subsection{Sarcófagos}

As pessoas mais ricas, desejando mostrar seu status social, foram inumadas em sarcófagos. Os modelos descobertos são diversos, alguns muito sóbrios, com apenas o texto, como o sarcófago de Calpurnia, do final do século II / século III; outros mais ricamente ornamentados, como o sarcófago do triunfo de Baco (Fig. 7), do início do século III, de mármore, importado de Carrara (Savay-Guerraz 2013:122). Estes sarcófagos estavam colocados em mausoléus. Em 1870, foi descoberto, na rua de Marseille, na margem esquerda do rio Ródano, uma tumba monumental "quase completa", incluindo um mausoléu, uma inscrição funerária, três sarcófagos (o principal e dois menores), os quais são cubas de três crianças da alta sociedade de Lugdunum: o principal é de Quintus Acceptius Venustus, os menores são de seu irmão e de sua irmã adotivos. O sarcófago principal é datado estilisticamente do início do século III (Lasfargues 2000:32-33; Savay-Guerraz 2013:43).

\subsection{Mausoléus}

O uso dos mausoléus é oriundo da Itália. As aristocracias italianas, seduzidas pelos modelos de arquitetura funerária que haviam sido descobertos durante as conquistas orientais do século I e II a.C., as colocaram em prática no final da República ou no início do período Augustano, denotando que essa moda se propagou rapidamente nas elites provinciais (Melmoth 2009-2010: 29). Os patrocinadores dessas construções funerárias orgulhosas e ostensivas estavam ansiosos para exibir o status e o sucesso de suas famílias.

O mais antigo mausoléu romano conhecido em Lyon é talvez aquele que a tradição chama de "túmulo dos Dois Amantes". Até o início do século XVIII, foi visto na margem direita do rio Saône, na entrada norte de Lyon, tendo sido destruído em 1707 pelo fato de obstruir a circulação da cidade. Ele é atualmente conhecido por uma gravura (Fig. 8). A função desse pequeno monumento é um enigma, sua localização, no cruzamento de duas estradas, e a ausência de inscrição funerária, levaram alguns a ver um pequeno santuário de encruzilhadas. Esta hipótese foi rejeitada por aqueles que o consideraram um mausoléu. No entanto, a sua forma e localização fora da cidade, ao longo de um caminho que corre paralelo ao rio Saône, seria apropriado para um túmulo. $\mathrm{O}$ seu nome se deve a uma lenda popular que relata que dois

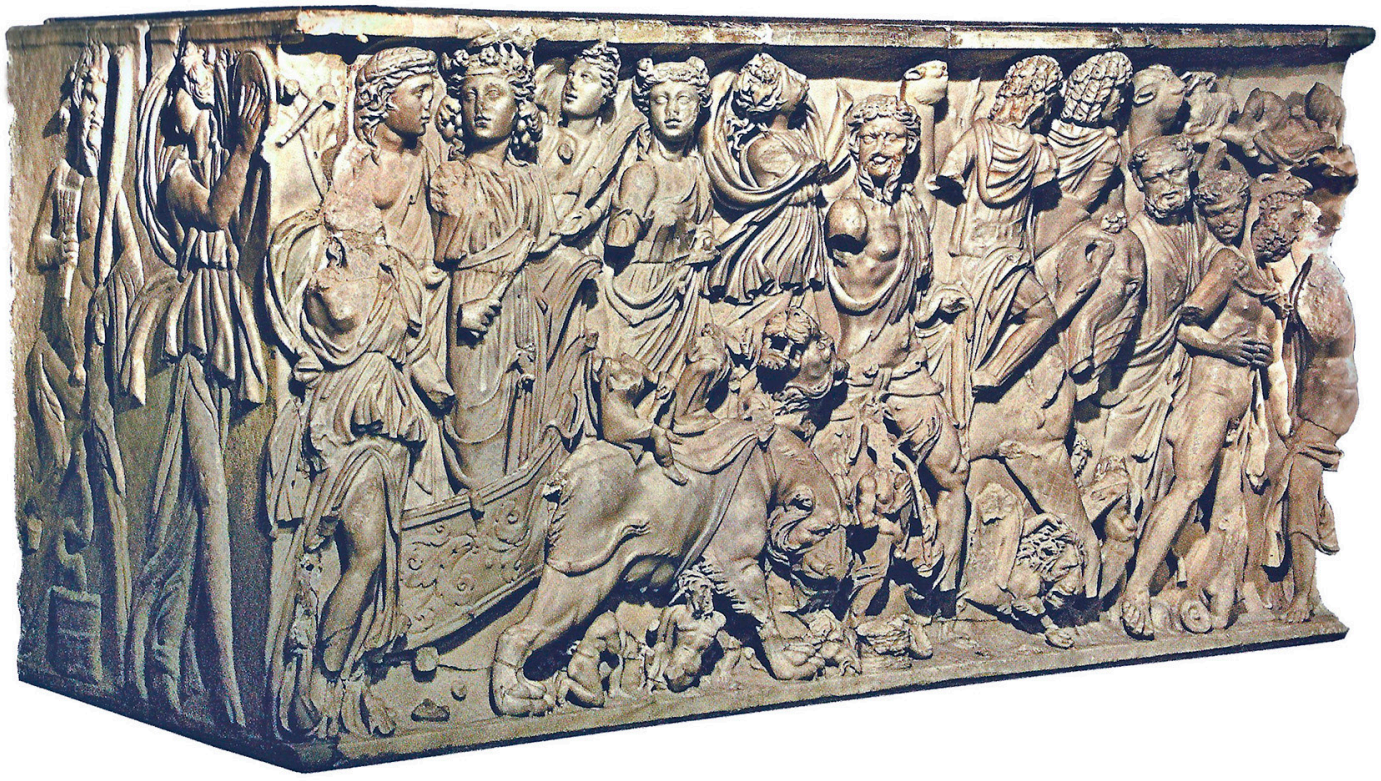

Fig. 7. Sarcófago do triunfo de Baco. Museu galo-romano de Lyon-Fourvière. NEsp., II, 239. 
amantes, depois de terem se procurado ao redor do mundo, teriam morrido de alegria se encontrando em Lyon. Assim, o enterro comum os teria unidos na morte (Fellague 2009:125-128).

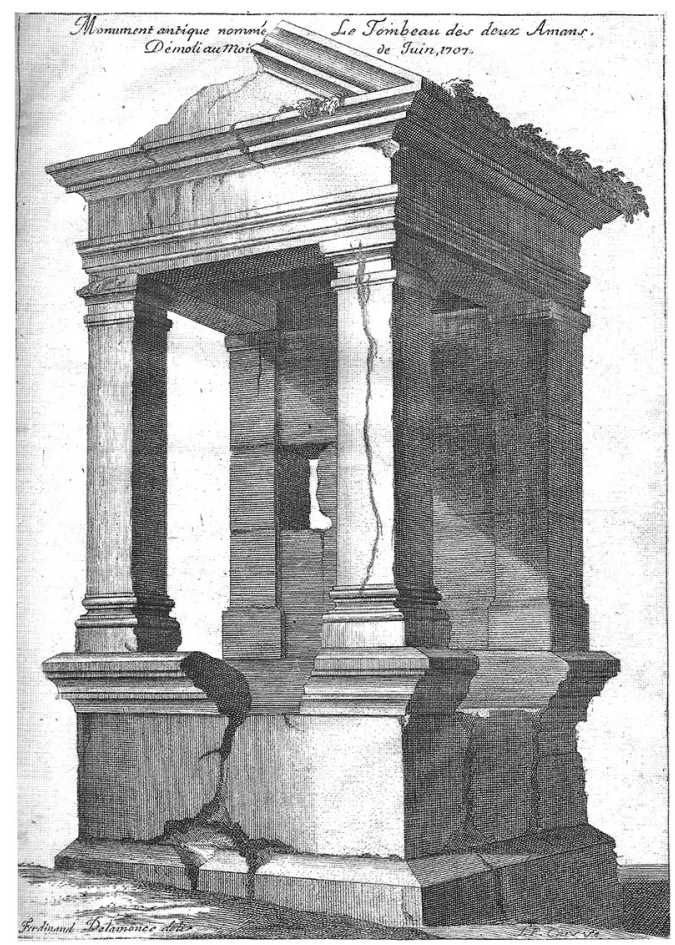

Fig. 8. Gravura de 1728 de F. Delamonce do túmulo dos Dois Amantes (Fellague 2009: 126).

Em Lyon, a monumentalidade das construções é reforçada pela escolha da localização. Os mausoléus de Trion, descobertos no século XIX, foram construídos na beira de uma estrada localizada na extensão do decumanus da cidade, "a cenografia, aqui, é exaltada pela paisagem, [...] os túmulos são erguidos abaixo de uma rampa que teve que subir para chegar até a cidade. Eles são colocados perto da encruzilhada para onde convergem as principais estradas do Reno e do Oceano, Aquitânia, Narbonense, bem como a rota que restauramos ao longo do flanco sudoeste do planalto. Colocados um do lado do outro [...] eles conferiam à via o aspecto de uma majestosa alameda monumental. Para qualquer um que chegasse a Lugdunum, esses monumentos permaneciam como poderosos sinais nos portões da cidade." (Laurence Tanoy in: Melmoth 2009-2010:32).
Cerca de vinte mausoléus estão identificados em Lyon. Esses exemplos mostram um fenômeno que surgiu cedo e durou até o século III (Tranoy 2009:90-92).

\subsection{Libações}

As descobertas de fornos culinários e grandes quantidades de louça não queimada estão relacionadas à prática de refeições fúnebres que as famílias costumavam consumir regularmente nas sepulturas. Outros ritos comemorativos deixaram vestígios arqueológicos, dentre eles, principalmente as libações. Elas geralmente consistem em derramar vinho sobre os restos do morto. Este rito explica os numerosos dispositivos ligando a sepultura ao exterior, como mostram, por exemplo, os vasos do ossuário com tampas perfuradas. Na rua Rochette-Chevrier, um depósito do final do século II / início do século III, é associado a uma ânfora voluntariamente furada para ser usada como tubo ligando o depósito ao exterior.

\section{Conclusão}

O corpus epigráfico relativo a Lugdunum é excepcional. Devido ao número de epitáfios encontrados, os ritos funerários romanos começaram a ser estudados muito cedo em Lyon. Apesar disso, foi necessário esperar o desenvolvimento da arqueologia preventiva e de resgate, nos anos 1980, para ver a arqueologia funerária se tornar uma especialidade incluindo os dados da arqueo-antropologia e de disciplinas naturalísticas. Considerando todas essas informações, é possível apresentar algumas conclusões.

As primeiras etapas dos ritos (velório e cortejo fúnebre) são difíceis de apreciar arqueologicamente. Na maioria das vezes, foi descoberto apenas o material usado para a preparação do corpo (estrigilo, balsamários, frascos de perfume). Esses objetos, que se tornaram fúnebres, foram encontrados em túmulos ou fossas de cremação. No entanto, a descoberta de uma máscara funerária de uma menina de 10 anos é muito rara e comovente. 
As escavações realizadas levam a abandonar os clichês difundidos pelos antigos manuais. Todos os túmulos e sepulturas não estavam estritamente localizados ao longo das vias ou em necrópoles bem definidas. Pelo contrário, a arqueologia mostra situações muito diversas, escapando de qualquer codificação e evoluindo ao longo do tempo. Os fornos culinários, a louça, os dispositivos para as libações refletem o banquete funerário e as comemorações das famílias.

A cremação foi majoritária em Lugdunum, até a metade do segundo século e sumiu completamente no século quarto, substituída pela inumação. As escavações mostraram uma grande diversidade nos tipos de depósito de cremação e inumação, do simples enterro ao mausoléu, dependendo do nível social da pessoa. Cerca de vinte mausoléus estão identificados em Lyon e datam do início do império até o século III. Dentre os túmulos infantis descobertos, foi encontrado o uso da ânfora como caixão de bebê, prática comum na Gália Narbonense durante o final da antiguidade.
Os epitáfios marcaram a localização das sepulturas e, a partir do final do século I, aparece, frequentemente, nas tumbas de Lugdunum, a representação da ascia. Esta ferramenta se tornou norma a partir do século II, mas seu significado permanece enigmático até hoje. Os textos funerários costumavam começar pela dedicatória aos deuses Manes, abreviado como DM. Apesar da grande quantidade de monumentos funerários, poucos retratos funerários foram descobertos em Lyon.

A partir do século IV, o desenvolvimento do cristianismo muda as práticas funerárias. Os monumentos em forma de altares desaparecem, o epitáfio agora é gravado em uma modesta placa e a tipografia perde em qualidade. Às vezes, as inscrições são acompanhadas de símbolos cristãos (pombas, espigas de trigo, vinho). A existência terrestre não é mais lembrada, doravante a profissão do falecido ou as circunstâncias de sua morte não são mais mencionadas (Savay-Guerraz 2013:124). As práticas são outras.

ROLLAND, Y. The funerary rituals in Lyon in Roman times. R. Museu Arq. Etn. 32: 108-119, 2019.

Abstract: Lugdunum, today Lyon, France, was one of the most important cities of the Roman empire. The interest for the Roman cult to the dead is old and confused, from the XVI century, with the study of inscriptions. Of the approximately 900 texts listed in Lyon, the epitaphs represent about $70 \%$ of the corpus. But despite this epigraphic richness, we had to wait for the end of the twentieth century so that anthropological remains and the deposits of all kinds that accompany them are research subjects per se. In the light of these new contributions we will try to portray the funeral practices of a powerful provincial city.

Keywords: Lugdunum; Cremation; Burial; Epitaphs; Mausoleums; Libations.

\section{Bibliografia abreviações}

AD: Allmer A., Dissard, P. 1889-1890. Inscriptions antiques. Musée de Lyon, t. II et t. III, Delaroche et Cie, Lyon.

AE : Année épigraphique.

CIL: Corpus Inscriptionum Latinarum.
ILTG: Wuilleumier, P. 1963. Inscriptions latines des Trois Gaules (Gallia suppl. 14), Paris.

NEsp: Lavagne, H. (Dir.) 2006. Nouvel Espérandieu II, Recueil général des sculptures sur pierre de la Gaule. Paris. 


\section{Referências bibliográficas}

Bérard, F. 2005. L'épigraphie: une mine d'informations très variées. In: Savay-Guerraz, Hugues (Dir.) Rencontres en Gaule romaine. Infolio. Lyon: 34-37.

Bérard, F. 2009. Quand les morts dialoguent avec les vivants. In: Goudineau, Ch. (Dir.) Rites funéraires à Lugdunum. Errance, Paris: 145.

Blaizot, F. 2009. Rites et pratiques funéraires à Lugdunum du $\mathrm{I}^{\mathrm{er}}$ au IV $\mathrm{IV}^{\mathrm{e}}$ siècle. In: Goudineau, Ch. (Dir.) Rites funéraires à Lugdunum. Errance, Paris: 154-186.

Boyer, R. 2009. Le coffret d'un oculiste déposé dans un bûcher du site de la Favorite I. In: Goudineau, Ch. (Dir.) Rites funéraires à Lugdunum. Errance, Paris: 113-114.

Burnand, M.; Burnand, Y. 1976. L'autel funéraire d'Aufidia Antiochis à Lyon. Gallia, 34-2: 293 310.

Fellague, D. 2009. Les mausolées de Lugdunum. In: Goudineau, Ch. (Dir.) Rites funéraires à Lugdu. num. Errance, Paris: 116-133.

Lasfargues, J. 2000. Lugdunum, des objets qui racontent l'Histoire. Edition Média Conseil Communication, Lyon.

Laubry, N. 2005. Primilla, jeune fille lyonnaise de bonne famille. In: Savay-Guerraz, H. (Dir.) Rencontres en Gaule romaine. Infolio. Lyon: 78-81.
Laubry, N. 2009. Les inscriptions funéraires des monuments lyonnais. In: Goudineau, Ch. (Dir.) Rites funéraires à Lugdunum. Errance, Paris: 134-153.

Melmoth, F. 2009-2010. Les mausolées en Gaule romaine. L'archéologue, $\mathrm{n}^{\circ}$ 105, décembre 2009. janvier 2010: 28-38.

Pérez, M-F. 1998. L'archéologie à l'Académie de Lyon au XVIII siècle: tradition et innovation. In: La fascination de l'antique, 1700-1770, Rome découverte, Rome inventée, Somogy éditions d'art, Paris, Musée de la civilisation gallo-romaine, Lyon: 158-161.

Poux, M. 2009-2010. Le dernier voyage, de la veillée funèbre au tombeau. L'archéologue, $\mathrm{n}^{\circ} 105$, décembre 2009 - janvier 2010: 14-17.

Savay-Guerraz, H. 2009. Les découvertes funéraires à Lyon des Antiquaires aux fouilles récentes. In: Goudineau, Ch. (Dir.) Rites funéraires à Lugdunum. Errance, Paris: 63-81.

Savay-Guerraz, H. 2013. Le musée gallo-romain de Lyon. Fage éditions, Lyon.

Tranoy, L. 2009. À Lugdunum: espaces des morts, espaces des vivants. In: Goudineau, Ch. (Dir.) Rites funéraires à Lugdunum. Errance, Paris: 83-106.

Voinot, J. 2011. La trousse d'oculiste de Lyon. In: Dasen, V. (Resp.) Quoi de neuf docteur: la médecine à l'époque romaine, Lyon: 24. 